Questions vives

\section{Questions Vives}

Recherches en éducation

Vol. $9 n^{\circ} 19$ | 2013

Éducation routière, changement de comportement et formation à la conduite : constat, enjeux et transformations

\title{
The reduction of novice drivers' accidents requires improved perception and reduced acceptance of risk
}

Les accidents de jeunes conducteurs peuvent être prévenus par une amélioration de la perception des risques en même temps qu'une baisse du niveau de risque accepté

\section{Gerald J.S. Wilde}

\section{(2) OpenEdition \\ Journals}

\section{Electronic version}

URL: http://journals.openedition.org/questionsvives/1266

DOI: 10.4000/questionsvives.1266

ISBN: 978-2-8218-1394-6

ISSN: $1775-433 \mathrm{X}$

\section{Publisher}

Université Aix-Marseille (AMU)

\section{Printed version}

Date of publication: 15 July 2013

Number of pages: $17-35$

ISBN: 978-2-912643-43-8

ISSN: 1635-4079

\section{Electronic reference}

Gerald J.S. Wilde, "The reduction of novice drivers' accidents requires improved perception and reduced acceptance of risk », Questions Vives [Online], Vol.9 n 19 | 2013, Online since 15 July 2013, connection on 30 April 2019. URL : http://journals.openedition.org/questionsvives/1266 ; DOI : 10.4000/questionsvives.1266

This text was automatically generated on 30 April 2019. 


\title{
The reduction of novice drivers' accidents requires improved perception and reduced acceptance of risk
}

\author{
Les accidents de jeunes conducteurs peuvent être prévenus par une amélioration \\ de la perception des risques en même temps qu'une baisse du niveau de risque \\ accepté
}

Gerald J.S. Wilde

\section{Introduction}

1 We know that beginner drivers are overrepresented in national road accident statistics. Drivers under age 25 commonly account for about twice as many accidents as their proportion in the total driver population, while their accident involvement diminishes with every additional year of driving (Mayhew, Simpson \& Pak, 2003; Claret \& al., 2003; Shope \& Bingham, 2008). We know, too, that about one-half of the overrepresentation of novice drivers in the accident statistics is due to inexperience, and the other half to characteristics associated with being young (Select Committee, 1977). Lack of experience implies a lower level of driving skill; we will argue here that this is largely due to (a) a salient deficiency in the ability of beginner drivers to recognize risk as more experienced drivers do (Pradhan, Pollatsek, Knodle \& Fisher, 2009), and (b) overconfidence in their ability to handle the challenges to their safety; and not to their limited vehicle-handling skills. We, therefore, first describe a teaching technique to help accelerate the acquisition of risk-perception skills in novice drivers.

2 Secondly, we argue - as we have done elsewhere (Wilde, 1997, 2012) - that the age-related overrepresentation of young drivers in the accident statistics is due to a higher-thanaverage level of willingness to rake risks. We discuss the major determinants of risk acceptance and present incentives for accident-free performance as the most effective 
method for bringing down the accepted level of risk while driving, and thus the frequency of accidents.

\section{Requirements for keeping accident risk at the level accepted}

There is a hierarchical set of conditions that must be fulfilled for a driver to reduce the likelihood of a potential accident due to his or her own doing (see Figure 1). Obviously, (1) the driver must be awake. But to be awake is not enough. A driver may well be fully awake, yet inattentive to the driving task and paying attention to other things, for instance, the cellular telephone, the radio or conversation with a passenger.

Thus, (2) the driver must also be attentive to the traffic situation. But paying attention to the traffic situation is not enough, because the driver may not have the sensory abilities (vision and hearing, among other things) to clearly perceive the danger-relevant features of the traffic situation.

Thus, (3) the driver must also have the necessary sensory abilities. But having the necessary sensory acuity is not enough, because the driver may fail to be aware of the amount of risk that is contained in the traffic situation he or she perceives. Risk perception, like the perception of beauty, is a product of experience and reasoning, however rudimentary, intuitive or subconscious these may be.

Thus, (4) the driver also has to be able to infer the amount of accident risk that is con tained in the traffic situation. But risk recognition is not enough, because, for the driver to be motivated to take action to reduce the accident risk, the amount of risk acknowledged must be greater than the level of risk the driver is willing to accept.

7 A further condition is, then, that (5) the risk must be greater than the driver is willing to tolerate. But the wish to reduce the risk is not sufficient, because the driver may or may not have the ability to decide what should be done in order to reduce the risk.

Therefore, (6) the driver also has to have the necessary decision-making skill for risk reduction. But to have the decision-making skill is not enough, because even the driver who knows what ought to be done may not have the vehicle-handling skill to carry out the necessary manœuvre. Hence, (7) the driver must also have the necessary vehiclecontrol skill.

If all of the above conditions are fulfilled, the driver may be called "safe", meaning that his or her actual risk is equal to, or smaller than, the level of acceptable risk in the driver's own judgement; and thus the driver feels "safe enough." One logical implication of this reasoning is that the average accident risk actually incurred by the collective of road users equals the average level of accident risk they find acceptable, unless, on average, they either overestimate or underestimate actual accident risk.

10 This, in fact, is a major contention of risk homeostasis theory (Wilde, 1982, 1988, 2001,2012), but this theory will not be the central focus of discussion in this presentation. Instead, we will focus on its implications for educational efforts aimed at improving novice drivers' perception of actual risk through driver training and with motivational interventions intended to lower their level of accepted risk by means of safety incentive programmes. 
Figure 1: Requirements drivers must fulfill to keep accident risk at the level they accept, i.e., "safe enough."

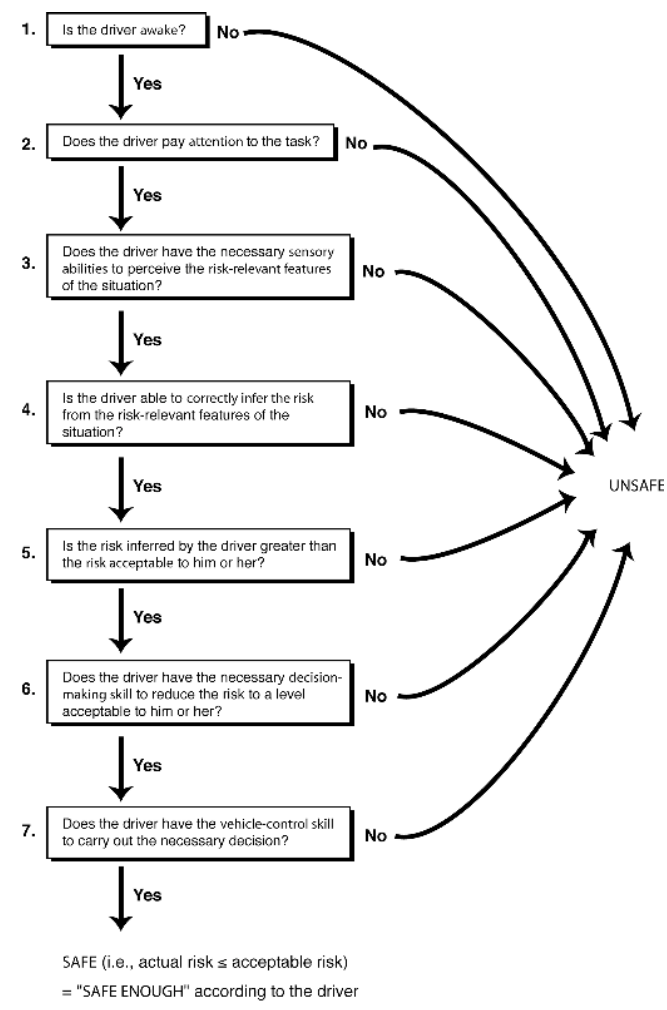

11 The simple logic presented in Figure 1 might suggest that there are as many as seven different factors involved in accident avoidance. That this is a misconception, however, becomes apparent when one reads Figure 1 from the bottom up and realizes that these factors do not operate independently of one another. If a person's vehicle-handling or decision-making skills are poor, that person's level of perceived risk should be high, and if it is not, this reflects overconfidence in one's skills. The same holds for sensory abilities. To be colour-blind or hard of hearing does not imply a significant increase in accident liability, provided the driver considers these handicaps in the estimation of risk. Poor night vision will not increase a person's accident risk unless the person is unaware of it or is willing to accept high levels of accident risk by driving in the dark. Deficiencies in skills and sensory functioning, all other things being equal, can increase a person's accident likelihood only to the extent that these deficiencies are underestimated by the person in question, and thus lead to an inappropriately low level of perceived risk. Several authors have stressed the critical importance of the driver being able to correctly assess his or her own competence at the driving task (e.g., Brown, Groeger \& Biehl, 1988; Kuiken \& Twisk, 2001).

12 Poor skill will not enhance a person's accident risk if that person is fully aware of his or her poor skill, because-risk acceptance level being the same-that person is less likely to engage in manœuvres he or she cannot handle very well. It is not surprising, therefore, that sensory abilities and other driving skills have generally been found to show no association, or very weak association, with accident involvement (Shinar, 1978; Grayson \& Noordzij, 1990; Ball \& al., 1993).

13 Moreover, better-than-average driving skill may lead to worse-than-average accident likeli hood, because the driver is being lulled into an illusion of safety. This factor is a common 
explanation for the fact that better-than-average driver training has repeatedly been found to be followed by worse-than-average accident involvement in Canada, the US and Europe (Skelly, 1968; Jonah, Dawson \& Bragg, 1982; Lund \& Williams, 1985; Lund, Williams, \& Zador, 1986; Brown \& al., 1988; Potvin, Champagne \& Laberge-Nadeau, 1988). As has been said by an Australian driver educator: "Strong motivation makes up for weak skills better than strong skills make up for weak motivation. Without strong motivation to reduce risk, advanced skills training can lead to more crashes, not fewer" (Jerrim, 1996).

Similarly, the authors of a Norwegian study not only found that mandatory driver training on slippery roads for truck drivers failed to reduce their accident risk, but also that, according to some of the analyses, the accident risk actually increased as a result of the course. As an explanation it was suggested "[...] that the course has a larger effect on the [learners'] belief in their abilities of driving on slippery roads, than on their actual abilities." (Christensen \& Glad, 1996). Approximately 20 years earlier, two other Norwegians had come to approximately the same conclusion (Marek \& Sten, 1977).

Inattentiveness to the driving task is undoubtedly a frequent immediate cause of accident, but is it also a root cause? Inattentiveness implies either that the driver estimated the risk of accident as very low and permitted himself or herself to pay more attention to other things, or that the driver considered other things to be at least temporarily more important than safety, thereby accepting a higher level of accident risk.

Finally, lapses in wakefulness during driving will not occur unless the driver underestimated or accepted the chances of falling asleep behind the wheel. Here again, the underlying cause is either risk underestimation or increased risk acceptance.

It would thus appear that the seven factors in our original analysis shrink to only two that are truly relevant to increased accident likelihood. Further, it would seem entirely reasonable to expect that individuals with a very low risk acceptance will be motivated to ensure that they do not underestimate risk. Consequently, only one dominant factor re mains: the level of risk acceptance. This is precisely the contention of risk homeostasis theory (Wilde, 1988, 1994, 2001, 2013), sometimes known as risk compensation theory, or among some economists as the "offsetting behaviour hypothesis" (Peterson, Hoffer \& Millner, 1995).

\section{Training of appropriate risk perception}

From the above considerations it would seem obvious that driver risk perception and its assessment by the teacher and improvement should have a centre stage position in the design of driver education programmes.

Driving educators may, however, have major difficulties in assessing the appropriateness of a student's risk perceptions. After all, these are "all in the head" of the student and not necessarily obvious in his or her behaviour. During in-car training in traffic there are so many things going on that it is not possible for the student to report to the educator on everything she or he sees that is relevant to the driving. In fact, the teaching procedure, called "commentary driving," which requires the student do this quite demanding task, may interfere with safe vehicle control when applied to beginning drivers. It is, therefore, a useful educational technique, but only for drivers who are already experienced and 
have sufficient spare mental capacity to accomplish the task of making elaborate ongoing commentaries (Marek \& Sten, 1977). It is possible, however, to greatly simplify the task of commentary driving for use with novice drivers, and it can be focused more sharply on risk perception in particular.

Trainee drivers are asked to rate the amount of risk they perceive at any time on a verbal scale, e.g., from 1 to 7, where 1 means "zero collision risk" and 7 stands for "extremely dangerous". Students are instructed to continuously monitor the risk they perceive, but to report to the instructor only when they perceive a change in risk, or when the teacher asks what the rating is. Thus, the teacher (or the supervising parent; Gregersen, Nyberg \& Berg, 2003) has an opportunity to check the student's hazard perception against his or her own more expert evaluation and is thus in a position to address and correct any discrepancies.

21 The practice of ongoing rating of risk is readily performed by any driver and not at all demanding. This is not surprising, because risk monitoring is what the driver is already doing anyway - at least according to risk homeostasis theory -; it is an integral part of the task of driving. What is different is merely that the driver is asked to verbally quantify the degree of risk experienced on a numerical scale. Various studies report that individual differences in verbal risk ratings show considerable between-rater reliability when asked to assess the risk while driving road sections of greater or lower past accident frequencies (Ganton \& Wilde, 1971; Moran, 1983; Grant \& Wilde, 1985; Wilde, 2012). Verbal risk ratings while driving have been shown to be sensitive to traffic events and changes in traffic configurations, variations in following distance and overtaking (Wilde \& Niepold, 1973).

These ratings are also consistent with psycho-physiological functions that are indicative of experienced fear. Increases in risk ratings coincide with increases in the electrical conductance of the skin without being confounded by any motor activity of the driver on the vehicle controls, as records of electrical conductance of the skin tend to do (Heino, van der Molen \& Wilde, 1994).

There is one study that involved verbal risk ratings that may well be particularly relevant to driver education. In that study it was found that inexperienced drivers' danger ratings tend to agree more with other inexperienced drivers' ratings than with those of ex perienced drivers. Similarly, ratings by experienced drivers do agree more with those by other experienced observers than they do with those of inexperienced drivers. In simpler words: drivers of similar levels of experience show greater similarity in the amount of risk they perceive (Ganton \& Wilde, 1971). In a situation of traffic conflict, therefore, experienced drivers would be expected to be better able to predict what another experienced driver will do to avoid a collision, and thus be more able to make the appropriate crash-avoidance response on their own part. Similarly, inexperienced drivers likely would predict the reactions of other inexperienced drivers more accurately than they would predict those of experienced ones.

Other studies have also noted that there are differences in risk perception between younger and older drivers. Finn \& al. (1986) questioned their American subjects on accident involvement and had them rate the riskiness of traffic situations in still photographs as well as videotapes. Significant differences between the young and the more experienced drivers were observed. This was also found to be true for the particular contributing factors to accidents (Shope \& Bingham, 2008). Age differences in risk perception were also observed in Britain (Brown \& Groeger, 1982). Delhomme \& Meyer 
(1995) obtained similar results in France, and so did Tränkle, Gelau \& Metker (1990) in Germany, and Borowsky, Shinar \& Oron-Gilad (2010) in Israel.

In addition, the fact that certain types of accidents are more typical for younger drivers than for the driver population as a whole is well established (see e.g., Lonero \& al., 1995; Lam, 2003).

There are thus plausible reasons for hypothesizing that the accident rate of novice drivers would be lower if only novice drivers were making use of the roads. Apart from the role played by inexperience per se, the experience mix in the collective of road users would seem to contribute to accident likelihood.

\section{The reduction of risk acceptance}

While appropriate risk perception would seem desirable from a safety point of view, it does not necessarily lead to accident reduction. For one thing, although training in hazard perception would be expected to lead to increases in the level of risk perceived by many drivers, some novice drivers might learn that certain traffic situations and manœuvres are not as dangerous as they thought they were. Consequently, this subgroup of drivers might expose themselves more to actual danger as a result of hazard perception training and their accident rate would increase.

Further, and more importantly, it should be noted that to perceive a risk does not imply that one will reject it. Whether this happens or not depends upon the level of risk the driver is willing to accept, and this depends on the following four factors:

a. the expected benefits of risky behaviour alternatives (e.g., gaining time by speeding, longer distances driven per time unit, sensation seeking, peer approval from the young, "macho" image, practice "near the edge," reactance - that is the inclination to go against the established rules and regulations of society in order to assert one's psychological independence and autonomy (Wilde, 2001, 2012, Section 11.2),

b. the expected costs of cautious behaviour alternatives (e.g., using an uncomfortable seatbelt, longer travel time, boredom, "wimpy" image, peer pressure problems, less practice "near the edge"),

c. the expected benefits of cautious behaviour alternatives (e.g., avoiding damage and injury, an insurance discount for accident-free driving, fuel and equipment savings), and

d. the expected costs of risky behaviour alternatives (e.g., a fine for jumping a red light, a fine for speeding, loss of safety awards, possible damage and injury, high fuel and equipment wear costs).

The accepted (tolerated, preferred, desired) level of risk - also known as the "target level of risk" (Wilde, 2001, 2012) - will increase as the weight of the first two factors increases, and be reduced as the last two become more important: the traffic accident likelihood of drivers will rise or fall accordingly. Any discrepancy that may occur between the amount of risk drivers perceive and the amount of risk they accept serves as the "decision rule" for taking either riskier or more cautious action (van der Molen \& al., 1988; Tränkle \& Gelau, 1992).

The target level is not fixed for all situations and all times (homeostasis being a process, not an outcome), because it depends on variation in the four utility factors mentioned above. It is obvious that these change by the state of the economy (Wilde, 2012, Chapter 5) or can be modified by deliberate actions by insurance companies, governments or other 
safety agencies. Drivers' motivation to avoid accidents can be enhanced by countermeasures that take the form of increasing the expected benefits of safe conduct, as well as by those that enhance the expected costs of risky behaviour: reward and punishment in other words. But not all "motivational" countermeasures can be expected to work towards greater safety, as we shall see.

\section{Safety incentive programmes} incentives for accident-free operation as an approach to accident prevention. This appears to be a truly international phenomenon: this author has seen reports on this topic in Dutch, English, German, Norwegian, Spanish, Swedish and Russian.

explains this interest? On the one hand, one could cite the large and still increasing amount of empirical evidence compiled in occupational, clinical and health psychology that shows the fruitfulness of the behaviour modification approach to the treatment of dysfunctional conduct and the shaping of desirable behaviours. On the other hand, one could point at indications of growing disappointment with the traditional approaches to accident prevention. Behaviour modification, with its focus upon motivation, is indeed quite different from the traditional "Triple $E$ " approach towards road and occupational safety: Engineering, Education and Enforcement. Engineering can improve the opportunity to be safe and education can enhance the ability to be safe, but neither necessarily increases the desire to be safe. So, to the extent that safety is actually determined more by the desire to be safe than by the physical opportunity that is offered or by the level of skill, the introduction of accident countermeasures of the traditional engineering and education varieties cannot be expected to reduce the accident rate per head of population (Wilde, 1988, 2001).

33 Thus, the art of effective safety management appears to depend more upon the art of effectively reducing the level of risk that people accept on the job, or on the road and elsewhere rather than upon training or technology.

\section{To reward or to punish?}

The notion that safety may be enhanced by acting upon motivation has, of course, a long history, as is clear from the universal presence of punitive law.

Although enforcement of punitive law is one of society's traditional attempts at motivating people towards safety, past evidence of its effectiveness has been less than overwhelming (OECD, 1974; Carr, Schnelle \& Kirchner, 1980; Bonnie, 1985). Even if selective enforcement can reduce the rate of a particular type of accident, e.g., drinkingand-driving accidents, this does not imply a reduction in the overall accident rate as the rate of sober accidents may increase (Rockerbie, 1980; Wilde, 1990). Some studies of 
enforcement report more positive effects, but these are usually marginal in size, local in scope, short-lived and expensive to implement (Mäkinen \& al., 2003).

The approach that takes the form of punishing people for specific unsafe acts also suffers from several other problems, some of which have been identified in the context of organizational psychology (Arnold, 1989):

a. The "self-fulfilling prophecy" of attribution: labelling people with undesirable characteristics may stimulate individuals to behave as if they had these characteristics. Thus, calling some people bad drivers may provoke some people to drive more poorly than they otherwise would.

b. The emphasis is on process controls, i.e., on specific behaviours, like using a piece of safety equipment or obeying the speed limit, instead of focusing on outcome: safety, that is, having no accident. Process controls are cumbersome to design and costly to implement. Moreover, process controls can never be totally exhaustive (i.e., cover all undesirable specific behaviours of all people at all time).

c. Punishment brings negative side effects. Punishment creates a dysfunctional organizational or social climate: resentment, uncooperativeness, antagonism, and sabotage. As a result, the very behaviour that was to be prevented may in fact be stimulated. Here we meet the phenomenon of reactance again. As it is particularly characteristic of the young (Hong, Giannakopoulos, Laing \& Williams, 1994), care should be taken not to provoke it in this age group.

37 In contrast, incentive programmes have both the effect for which they are intended as well as the positive side effect of creating a more favourable social climate (Steers \& Porter, 1991). Their effectiveness in enhancing safety is clearly established (Komaki, Barwick \& Scott, 1978; Haynes, Pine \& Fitch, 1982; Wilde, 1985; Fox, Hopkins \& Anger, 1987; McAfee \& Winn, 1989).

In a review of over 53 published evaluations of different types of occupational accident prevention, incentives were generally found more effective in enhancing safety than were engineering improvements, personnel selection, and other types of intervention which included disciplinary action, special licensing, and exercise and stress reduction programmes (Guastello, 1993).

\section{Cost-effectiveness of incentive programmes}

Accident reductions per head decreased to fractions between $50 \%$ and $20 \%$ of base rate are not uncommon in manufacturing, construction and other industry. In passing it should be noted that some $51 \%$ of all industrial accidents occur on the roads (Takala,1999) and thus that accident prevention efforts in the world of occupational and traffic safety should not be separated as if they were two totally different domains. The ratios between benefits (savings on accidents prevented) and programme costs are usually greater than 2 to 1 , meaning that industrial companies can make money on such accident prevention efforts (this is largely due to reduced fees to workers' compensation boards and other insurance in jurisdictions where insurance fees depend to the company's own accident record and not of that of the average record of the industry branch to which the company belongs).

These favourable effects endure over time. Incentive plans in two American mines were studied over periods of 11 and 12 years. In one mine the number of days lost due to accidents was reduced to about $11 \%$ of baseline, and in another, to about $2 \%$. Benefit/ 
cost ratios varied from year to year between 18 and 28 at one mine and between 13 and 21 at the other. There was no sign that the effectiveness of the incentive plans diminished over time at either mine (Fox \& al., 1987). Very high benefit/cost ratios have also been reported by others (e.g., Greenberg \& Baron, 1997).

Incentive programmes usually meet with approval from the people to whom they are addressed and in this respect, they compare favourably with the much less popular action of the law and of the police. To put it popularly: a small carrot is not only much better liked than a big stick. It is also much more effective. Only one negative side effect has been noticed so far, and that is the tendency of people to under-report accidents when incentive programmes are in effect. Fortunately, however, such underreporting has been found to occur with respect to minor accidents only (McAfee \& Winn, 1989). It is easy to conceal a minor mishap, not so a dead body.

\section{Requirements for effective incentive programming}

Past experience with incentive programmes shows that some programmes have had much greater impact than others. For instance, a German incentive plan, which promised professional truck and van drivers a bonus of DM 350 for each half-year of driving without being at fault in an accident, produced a reduction in direct accident cost to less than one-third in the first year of application and remained at that level for over three decades (Gros, 1989). In the California "good driver" experiment, in which drivers in the general population were offered free extension of their driver's licence by one year in return for each year of accident-free driving, the accident rate dropped by $22 \%$ in the first year of the programme, while the effect was particularly marked among young drivers (Harano \& Hubert, 1974). Accident reduction by as much as $35 \%$ was achieved by a Norwegian incentive program that offered rebates plus interest for accident-free beginner drivers (Vaaje, 1991). Thus, the need arises to identify the distinctive features of the more successful incentive schemes.

The following are among the typical features of the more effective incentive plans in the various published reports (bibliographic sources may be found in the following references: Wilde \& Murdoch, 1982; Wilde, 1985; McAfee \& Winn, 1989; Peters, 1991; Guastello, 1993; Wilde, 2001).

7.1. Leadership. Incentive programmes should be introduced and maintained with vigour, commitment and coherence. Workers or drivers should not only be informed of the programme in existence, but they should also frequently be reminded of it in attention-catching ways.

7.2. Operator participation in programme design. The incentive scheme should be developed in cooperation and consultation with those people to whom it will be applied. People are more likely to actually strive for goals they have helped define themselves (Latham \& Baldes, 1975; Komaki \& al., 1978). As the perceptions, values and motivations of the young differ from the population as a whole, care must be taken that these are accounted for in programme design. An incentive can only be an incentive to the extent that it is being experienced as an incentive by the target group. An "imposed" reward programme may lead to reactance and thus be counterproductive to safety. behavior. Incentive programmes should reward the outcome variable, the "bottom line" 
- the fact of not having caused an accident - not some process variable like wearing the seatbelt or helmet, driving when sober, obeying the speed limit, wearing safety glasses or hearing protection (as described, for instance, by Zohar, 1980). Rewarding specific behaviours does not necessarily strengthen the motivation towards safety, and a potential safety benefit due to an increased frequency of one specific form of 'safe' behaviour may simply be offset by road users less frequently displaying other forms of "safe" acting. "The risk is here that while the rewarded behavior may improve, other related safe behaviors may deteriorate."( McAfee \& Winn,1989).

7.4 Attractive awards. Incentive programmes can be expected to be more successful to the extent that they widen the utility difference between the perceived benefit of not having an accident and the perceived disadvantage of having an accident. Rewards for accident-free operation in industry have taken many different forms, ranging from cash to public commendation. They include trading stamps, lottery tickets, gift certificates, shares of company stock, extra holidays and other privileges.

Drivers have been rewarded with cash (Gros, 1989), automobile insurance rebates (Vaaje, 1991) and free licence renewal (Harano \& Hubert, 1974).

Awards do not have to be very large to be effective. In fact, a case can be made for relatively small awards being preferable. Small awards make it possible to hand out awards more frequently, they are probably less conducive to under-reporting of accidents, and they may foster the internalization of pro-safety attitudes through the process of "cognitive dissonance reduction." (Geller, 1990). When a modest reward changes a person's behaviour, that person may justify that change by reasoning that the change was for safety's sake rather than due to the insignificant inducement. No such internalization of pro-safety attitudes is necessary when the external inducement is large, because in that case it fully justifies the behaviour change. It should be noted, however, that the attitude-shaping effect of modest awards can only take place after the operators have changed their behaviour for whatever minor external inducement. So, the award should be big enough to achieve some behaviour change to begin with (Gregersen \& al., 1996).

In some cases a small material reward might imply a major social reward because of its "symbolic function" (Markus, 1990). Safe behaviour may thus become the "right thing to do" and add to the social status on those who behave safely. This might help explain why a modest incentive, such as the free licence renewal for one year, produced a major reduction in the accident rate of California drivers (Harano \& Hubert, 1974). With respect to the accident likelihood of novice drivers, it is also of special interest to note that this intervention had the largest effect upon young motorists (i.e., those under 25 year of age). To behave safely may have become less "sissy" in their eyes and more "sensible".

7.5. Progressive accumulation of safety credits. The amount of the incentive should continue to grow progressively as the individual operator accumulates a larger number of uninterrupted accident-free periods; e.g., the bonus for 10 uninterrupted years of accident-free driving should be greater than 10 times the bonus for one year of accidentfree driving (Wilde \& Murdoch, 1982). In Ontario, Canada, as well as in some other jurisdictions, it is common practice for insurance companies to offer fee discounts of increasing amounts, as the number of claim-free years increase. But this is true only for up to five years of accident-free driving, as if such discounts would have no accident-reducing effect beyond that period. 
What may be worse from the point of view of accident prevention is that drivers with five or more fault-free years who have a subsequent culpable accident, are not likely to actually incur an increase in insurance fees. The reason for an insurance company to have this "forgiveness clause" would seem to be that the driver in question is seen as a relatively "good risk" whose business would be sadly missed if it went to the competition. This practice, however, fails to bring the accident rate down to a level as low as it could have been otherwise.

7.6. Bonuses perceived as equitable. Those to whom it is addressed should perceive the incentive programme as equitable. The bonus should be such that it is viewed as a just reward for not causing an accident in a given time period. As chance plays a part in having or not having an accident, the actual receipt of the award may be made to depend upon the additional requirement that the accident-free driver in question also has no demerit points.

7.7. Bonuses perceived as accessible. Programmes should be designed such that the bonus is viewed as realistically attainable and not beyond reach. This is of particular importance if the bonus is awarded in a lottery system. Although lotteries make it possible to hand out greater awards, thus enhancing the attention-getting appeal of an incentive programme, fewer among the people who have accumulated the safety credit will receive the bonus. This, in turn, may discourage some people from making an active attempt to accumulate the safety credit to begin with (Bartels, 1974).

7.8. Short incubation periods. The specified time period in which the individual has to remain accident-free in order to be eligible for the bonus should be kept relatively short. Delayed rewards and penalties tend to be discounted and are thus less effective in shaping behaviour than more immediate consequences. Periods as short as one month have been used in industry. In the cited California experiment, those drivers whose licenses were coming up for renewal within one year after being informed of the incentive programme showed a greater reduction in accident rate than was true for people whose licenses did not have to be renewed until two or three years later.

7.9. Simple rules. The operational rules of the programme should be kept simple so that they are easily understood by all persons to whom the programme applies.

7.10. Rewarding group as well as individual performance. Incentive programmes should be designed such that they strengthen peer pressure towards the objective of having no accident. Thus, the plan should not only stimulate each individual operator's concern for her or his own safety, but also motivate her or him to influence peers so that their accident likelihood is also reduced. In industrial settings this is achieved by extending a bonus for accident-free performance of the work team in addition to the bonus for individual freedom of accidents, and the team bonus has been found to increase the competitive motivation towards winning the team award. In the context of road safety, this can be achieved by pitting all (young) drivers in one age group against another age group in the same community, or by organizing a safety competition between cities. Team awards add a material incentive to the motivation to act as "one's brother's and sister's keeper".

7.11. Rewarding multiple levels within the social structure. In industrial settings, not only are shop floor workers to be rewarded for safe performance, but also their supervisors and middle managers. This creates a more cohesive and pervasive safety orientation, also known as a "safety culture" (Guldenmund, 2000) within a company (Fox 
\& al., 1987; Bacher, 1989; Bruening, 1989; Synett, 1992). Thus, several links in the "line of command" should be made eligible for an award, not only those who stay out of accidents, but also those who are responsible for those who stay out of accidents. This consideration may have particular implication for the trucking industry (Rothe, 1991) as well as for safety competitions between different school boards, towns and cities.

7.12. Prevention of accident under-reporting. Thought should be given to the question of how to counteract operators' tendency not to report the accidents they have. That the institution of incentive programmes may stimulate that tendency seems to be the only currently identified negative side effect of such programmes (while occasionally moral objections have been raised against rewarding people for obtaining a goal they should aspire to on their own, without being "bribed into safety"). Some incentive programmes have clauses providing for deduction of safety credits in case accidents are not reported (Fox \& al., 1987).

60 7.13. Maximization of accident reduction versus maximizing benefit/cost ratios. In the planning of an incentive programme, thought should be given as to what actually constitutes its primary goal: the greatest possible accident reduction or a maximal benefit/cost ratio. Some programmes may reduce the accident frequency only slightly, but achieve this at a very low cost. The benefit/cost ratio may thus be higher than is true for another programme where the ratio between benefits and costs is lower, but which is capable of reducing the accident rate by a much greater degree. As distinct from the issue of the size of the benefit/cost ratio, the total amount of money saved may well be much greater in the latter case.

61 Consider the following example. Safety programme $A$ can save 700.000 Euros at an implementation cost of 200,000. Programme B can save 900.000 Euros at a cost of 300,000. In terms of benefit/cost A's ratio is 3.5, while B's ratio equals 3.0. Thus, against the benefit/cost criterion, $\boldsymbol{A}$ is superior, but if net savings are considered, the picture is different. While programme $A$ saves 700.000 minus 200.000 , or 500.000 Euros programme B saves 900.000 minus 300.000 , that is 600.000 Euros. In terms of net savings, the larger programme is to be preferred.

62 7.14. Research component. Like any other accident countermeasure, an incentive plan should not be introduced without prior research into its short-term and long-term feasibility, nor without prior research into its best possible form, nor without provision for scientifically adequate evaluation of its implementation costs and its observed effectiveness in reducing the accident rate. The knowledge base of the safety research and application community is unlikely to grow without proper evaluation and ready access to the results.

Without such research, the surprising effect of one particular reward programme would never have come to light. One might perhaps think that rewards for safety simply cannot have a negative effect, but there is one specific type in a series of California reward/ incentive programmes for the general driving public that produced worse subsequent driving records. In this programme, a benefit was given to drivers with no accidents on their records without their prior knowledge of that benefit coming to them. It took the form of an unexpected reward rather than an incentive, and this highlights the importance of the distinction for safety promotion and the usefulness of careful programme evaluation (Harano \& Hubert, 1974). The research that accompanied this California programme did go far enough to discover the counterproductive effect of the 
unannounced reward, but, unfortunately, it did not go far enough to reveal the reasons for this failure. At any rate, this finding, together with the significant beneficial effect of the California incentive programme mentioned at the start of this section, highlights the importance of the distinction between "incentive" and "reward". The term "incentive" refers to a pre-announced gratification or award extended to workers or drivers on the specific condition - that is likewise pre-announced - that they do not have an accident of their own fault within a specified future time period. A "reward" is a gratification that is not necessarily pre- announced. It may come unexpectedly, and without recipient being aware of conditions that had to be fulfilled.

\section{Concluding remarks}

In short, this article suggests that efforts should be taken to make novice drivers more sophisticated "risk managers". Two things are necessary for this purpose: better risk recognition and lower acceptance of accident risk. For each, we have made practical suggestions. Although it would seem quite plausible that training toward better risk recognition should lead to fewer accidents, this remains to be proven. The evidence for the effectiveness of incentive programmes in reducing risk acceptance, on the other hand, is overwhelming. One of the more comprehensive literature reviews on that topic contains the following statement: "The major finding was that every study, without exception, found that incentives or feedback enhanced safety and/or reduced accidents in the work place, at least in the short term. Few literature reviews find such consistent results" (Peters, 1991).

One part of the evidence we have discussed comes from industrial settings, and another part from road traffic. The types of gratification that have been extended to employees in industry may differ from the bonuses that can be offered to drivers in the general population, or to young drivers in particular in a given jurisdiction. The underlying principles, however, are the same. Creative design of incentive programmes specially tailored to novice drivers will be necessary. No less necessary is it that the input into incentive programming be professional. We have already given an example of a reward (not incentive) programme that actually turned out to be counterproductive to safety (Harano \& Hubert, 1974). Moreover, we have discussed programme characteristics that could have made past incentive schemes more effective than in fact they were. Behaviour modification techniques can be very powerful indeed. If they are to serve the intended purpose, their implementation should be founded on the best expertise and insights currently available.

We all know that policy makers in government and elsewhere are eager to be seen to be doing something about a matter of social concern, such as traffic safety. If a government wants to do more than that, and actually do something about the road accident problem, the logic of this article suggests that it should use its influence to stimulate its own agencies, the insurance and other industrial companies, cities, driving schools and parents to extend incentives to drivers for remaining without accident. 


\section{BIBLIOGRAPHY}

Arnold, H.J. (1989). Sanctions and rewards: Organizational perspective. In M.L. Friedland (Ed.), Sanctions and rewards in the legal system; A multidisciplinary approach. Toronto: University of Toronto Press.

Bacher, K. (1989). Erfahrungen mit dem Sicherheitswettbewerb "Sicher arbeiten und 100 Mark gewinnen” bei der Hoogovens Aluminiums Hüttenwerk GmbH. In Ludborsz, B. (Ed.), Psychologie der Arbeitssicherheit, 4. Workshop, 1988. Heidelberg: Roland Ansager Verlag, 345-346.

Ball, K, Owsley, C, Sloane, M.E., Roenker, D.L., \& Bruni, J.R. (1993) Visual attention problems as a predictor of vehicle crashes in older drivers. Investigative Ophthalmology and Visual Science, 34, 3110-3123.

Bartels, K. (1976). Über die Wirksamkeit von Arbeitssicherheitsprämien. Dortmund, Germany: Bundesanstalt für Arbeitsschutz und Unfallforschung, p. 15.

Bonnie, R.J. (1985). The efficacy of law as a paternalistic instrument. Nebraska Symposium on Motivation, 29, 131-211.

Borowsky, A., Shinar, D., \& Oron-Gilad, T. (2010). Age and skill differences in driving related hazard perception. Accident Analysis and Prevention, 42,1240-1249.

Brown, I.D., \& Groeger, J.A. (1988). Risk perception and decision taking during the transition between novice and experienced driver status. Ergonomics, 31, 585-597.

Brown, I.D., Groeger, J.A., \& Biehl, B. (1988). Is driver training contributing enough to towards road safety? In Rothengatter, J.A. \& de Bruin, R.A. (Eds.). Road users and traffic safety. Wolfeboro, New Hampshire, USA: Van Gorcum, 135-156.

Bruening, J.C. (1989). Incentives strengthen safety awareness. Occupational Hazards, Nov., 49-52.

Carr, A.F., Schnelle, J.F., \& Kirchner, R.E. (1980). Police crackdowns and slowdowns: a naturalistic observation of changes in police traffic enforcement. Behavioral Assessment, 2, 33-41.

Christensen, P., \& Glad, A. (1996). Mandatory course of driving on slippery roads for drivers of heavy vehicles. The effect on accidents. TÖI 334/1996, Transportökonomisk institutt, Oslo, Norway.

Claret P.L., Castillo J.d.D.L.d., Moleon J.J.J., Cavanillas A.B., Martn M.G., \& Vargas R.G. (2003). Age and sex differences in the risk of causing vehicle collisions in Spain, 1990 to 1999. Accident Analysis and Prevention, 35, 261-272.

Delhomme, P., \& Meyer, T. (1995). Évaluation de ses propres comportements de conduite : effets sur le contrôle subjectif et la régulation de l'activité. Paris : INRETS : Rapport 200.

Finn, P., \& Bragg, B.W. (1986). Perception of the risk of an accident by young and older drivers. Accident Analysis and Prevention, 18, 289-98.

Fox, D.K., Hopkins, B.L., \& Anger, W.K. (1987). The long-term effects of a token economy on safety performance in open pit mining. Journal of Applied Behavior Analysis, 20, 215-224. 
Ganton, N., \& Wilde. G.J.S. (1971). Verbal ratings of estimated danger by drivers and passengers as a function of driving experience. Report prepared for the Road and Motor Vehicle Traffic Safety Division, Ministry of Transport, Ottawa, Canada.

Geller, E. Scott (1990) quoted by Bruening, J.C. Shaping workers' attitudes toward safety. Occupational Hazards, 52, 49-51.

Grant, B.A., \& Wilde, G.J.S. (1985). Perceived risk: Its measurement and variability across four types of roadway. Proceedings, 18th Annual Conference of the Human Factors Association of Canada, Hull, Québec, Sept. 27-28, 39-42.

Grayson, G., \& Noordzij, P. (1990). Facteurs individuels et sociaux influençant la probabilité d'accidents. Proceedings, International Symposium organised by La Prévention Routière, May 16-18. Caen, France: Paradigme, 635-641.

Greenberg, J., \& Baron, R.A. (1997). Behavior in organizations: Understanding and managing the human side of work. Upper Saddle River, New Jersey: Prenctice Hall, p. 485.

Gregersen, N.P., Brehmer, B., \& Morén B. (1996). Road safety improvement in large companies: An experimental comparison of different measures. Accident Analysis and Prevention, 28, 297-306.

Gregersen, N.P., Nyberg, A., \& Berg, H.-Y. (2003). Accident involvement among learner drivers-an analysis of the consequences of supervised practice. Accident Analysis and Prevention, 35, 725-730.

Gros, J. (1989). Das Kraft-Fahr-Sicherheitsprogramm. Personalführung, No. 3, 246-249.

Guastello, S.J. (1993). Do we really know how well our occupational accident prevention programs work? Safety Science, 16, 445-463.

Guldenmund, F. W. (2000). The nature of safety culture: a review of theory and research. Safety Science, 34, 215-257.

Harano, R. M., \& Hubert, D.E. (1974). An evaluation of California's 'good driver' incentive program. Report No. 6. Sacramento: California Division of Highways.

Haynes, R.S., Pine, A.R.C. \& Fitch, H.G. (1982). Reducing accident rates with organizational behaviour modification. Academy of Management Journal, 25, 407-416.

Heino, A., van der Molen, H.H., \& Wilde, G.J.S. (1994). Electrodermal responses and verbal risk estimates as indicators of perceived level of risk during a car-driving task. In Trimpop, R.M., \& Wilde, G.J.S. Challenges to accident prevention: The issue of risk compensation behaviour. Groningen, the Netherlands: Styx Publications.

Hong, S, M., Giannakopoulos, E., Laing, D., \& Williams, N.A. (1994). Psychological reactance: Effects of age and gender. Journal of Social Psychology, 134, 223-228.

Jerrim, A. (1996). Trainers must meet behavior challenge. Driver/Education: An Independent Information Service, 6, 8-9.

Jonah, B.A., Dawson, N.E., \& Bragg, B.W.E. (1982). Are formally trained motorcyclists safer? Accident Analysis and Prevention, 14, 247-255.

Komaki, J., Barwick, K.D., \& Scott, L.R. (1978). A behavioral approach to occupational safety: Pinpointing and reinforcing safe performance in a food manufacturing plant. Journal of Applied Psychology, 63, 434-445.

Kuiken, M., \& Twisk, D., (2001). Safe driving and the training of calibration. R-2001-29, SWOV Institute for Road Safety Research, Leidschendam, the Netherlands. 
Lam L.T. (2003). Factors associated with fatal and injurious car crash among learner drivers in New South Wales, Australia. Accident Analysis and Prevention, 35, 333-340.

Latham, G.P., \& Baldes, J.J. (1975). The practical significance of Locke's theory of goal setting. Journal of Applied Psychology, 60, 122-124.

Lonero, L., Clinton, K., Brock, J., Wilde, G., Laurie, I. \& Black, D. (1995). Novice driver education: Model curriculum outline. AAA Foundation for Traffic Safety, 1440 New York Avenue, N.W., Suite 201, Washington, D.C. 20005, March 1995 (95 pages).

Lund, A.D., \& Williams, A.F. (1985). A review of the literature evaluating the Defensive Driving Course. Accident Analysis and Prevention, 22, 1-11.

Lund, A.K., Williams, A.F. \& Zador, P. (1986). High school driver education: Further evaluation of the DeKalb County study. Accident Analysis and Prevention, 18, 349-357.

Mäkinen, T., Zaidel, D. M., Andersson, G., Biecheler-Fretel, M. B., Christ, R., Cauzard, J. P., Elvik, R., Goldenbeld, C., Gelau, C., Heidstra, J., Jayet, M. C., Nilsson, G., Papaioanou, P., Quimby, A., Rehnova, V., \& Vaa, T. (2003).Traffic enforcement in Europe: effects, measures, needs and future. Brussels: European Commission under the RTD Programme of the 4th Framework Programme.

Marek, J., \& Sten, T. (1977). Traffic environment and the driver: Driver behavior and training in international perspective. Springfield, Ill.: Charles C. Thomas.

Markus, T. (1990). How to set up a safety incentive program. Supervision, July, 14-16.

McAfee, R.B., \& Winn, A.R. (1989). The use of incentives/feedback to enhance work place safety: A critique of the literature. Journal of Safety Research, 20, 7-19.

Mayhew D.R., Simpson H.M., \& Pak A. (2003). Changes in collision rates among novice drivers during the first months of driving. Accident Analysis and Prevention, 35, 683-691.

Moran, A. (1983). Drivers' mental load and subjective risk estimates while driving road sections of different accident histories. Proceedings, 15th Annual Meeting of the Human Factors Association of Canada, 72-75.

OECD - Road Research (1974). Research on traffic law enforcement. Paris.

Peters, R.H. (1991). Strategies for encouraging self-protective employee behavior. Journal of Safety Research, 22, 53-70.

Peterson, S., Hoffer, G. \& Millner, E. (1995). Are drivers of air-bag-equipped cars more aggressive? A test of the offsetting behavior hypothesis. Journal of Law and Economics, 38, 251-264.

Potvin, L., Champagne, F. \& Laberge-Nadeau, C. (1988). Mandatory driver training and road safety: The Quebec experience. American Journal of Public Health, 78, 1206-1209.

Pradhan, A. K., Pollatsek, A., Knodler, M., \& Fisher, D. L. (2009). Can younger drivers be trained to scan for information that will reduce their risk in roadway traffic scenarios that are hard to identify as hazardous? Ergonomics, 52, 657-673.

Rockerbie, R.A. (1980). Counterattack: Perspectives and assessment. Vancouver, British Columbia, Canada: Policy Planning Division, Ministry of the Attorney General.

Rothe, J.P. (1991). The trucker's world: Risk, safety and mobility. New Brunswick, N.J.: Transaction Publishers.

Select Committee on Highway Safety (1977). Final Report. Toronto: Government of Ontario, Canada, September, Exhibit III-2.

Shinar, D. (1978). Psychology on the Road: The human factor in traffic safety. New York: Wiley. 
Shope, J.T., \& Bingham, C.R. (2008). Teen Driving: Motor-Vehicle Crashes and Factors That Contribute. American Journal of Preventive Medicine, 35, Nº3, SUP, Note(s): S261-S271.

Skelly, G.B. (1968). Aspects of driving experience in the first year as a qualified driver. Report LR149. Crowthorne, United Kingdom: Road Research Laboratory.

Steers, R.M., \& Porter, L.W. (1991). Motivation and work behavior, 5th edition. New York: McGrawHill.

Synett, R.J. (1992). Construction safety: A turnaround program. Professional Safety, 37, 33-37.

Takala, J. (1999). Global estimates of fatal occupational accidents. Epidemiology, 10, 640-646.

Tränkle, U., Gelau, C., \& Metker, K. (1990). Risk perception and age-specific accidents of young drivers. Accident Analysis and Prevention, 22, 119-125.

Tränkle, U., \& Gelau, C. (1992). Maximization of subjective expected utility or risk control? Experimental tests of risk homeostasis theory. Ergonomics, 35, 7-23.

Vaaje, T. (1991). Rewarding in insurance: Return of part of premium after a claim-free period. Proceedings, OECD/ECMT Symposium on enforcement and rewarding: strategies and effects. Copenhagen, Denmark, Sept. 19-21, 1990.

Van der Molen, H.H., \& Bötticher, A.M.T. (1988): A hierarchical risk model for traffic participants. Ergonomics, 31, 537-555.

Wilde, G.J.S. (1982). The theory of risk homeostasis: Implications for safety and health. Risk Analysis, 2, 209-225.

Wilde, G.J.S. (1985). The use of incentives for the promotion of accident-free driving. Journal of Studies on Alcohol, Supplement No. 10, 161-168.

Wilde, G.J.S. (1988). Risk homeostasis theory and traffic accidents: Propositions, deductions and discussion of dissension in recent reactions. Ergonomics, 31, 441-468.

Wilde, G.J.S. (1990) Questioning the progress: The matter of yardsticks and the influence of the economic juncture. Proceedings, 11th International Conference on Alcohol, Drugs and Traffic Safety, Chicago, Illinois, Oct. 24-27, 106-114.

Wilde, G.J.S. (2001). Target risk 2: A new psychology safety and health. Toronto: PDE Publications. Also translated (by M. Camiolo) into French: Wilde, G.J.S. (2012). Le risque cible : une théorie de la santé et de la sécurité. Bruxelles-Fernelmont: E.M.E. Intercommunications.

Wilde, G.J.S. (1997). Two challenges to driver education: Improvement of risk perception and reduction of risk acceptance. In Schulz, U. (Ed.), Wahrnehmungs-, Entscheidungs- und Handlungsprozesse beim Führen eines Kraftfahrzeugs: Zum Gedenken an Ulrich Tränkle. Münster, Germany: LIT Verlag, 1997, pp. 15-40.

Wilde, G.J.S., \& Murdoch, P.A. (1982). Incentive systems for accident-free and violation-free driving in the general population. Ergonomics, 25, 879-890.

Wilde, G.J.S., \& Niepold, R. (1973). Estimation subjective du danger lors de manœuvres de dépassements en fonction de l'expérience du conducteur. First International Conference on Driver Behaviour, Zürich, Switzerland, Oct. 8-12. (abstract only published).

Zohar, D. (1980). Promoting use of personal protective equipment by behavior modification techniques. Journal of Safety Research, 12, 78-85. 


\section{ABSTRACTS}

We know that beginner drivers are overrepresented in national road accident statistics. Drivers under age 25 commonly account for about twice as many accidents as their proportion in the total driver population, while their accident involvement diminishes with every additional year of driving. We know, too, that about one-half of the overrepresentation of novice drivers in the accident statistics is due to inexperience, and the other half to characteristics associated with being young. Lack of experience implies a lower level of driving skills; we will argue here that this is largely due to (a) a salient deficiency in the ability of beginner drivers to recognize risk as more experienced drivers do, and (b) overconfidence in their ability to handle the challenges to their safety; and not to their limited vehicle-handling skills. We therefore, first describe a teaching technique to help accelerate the acquisition of risk-perception skills by novice drivers. Secondly, we argue that the age-related overrepresentation of young drivers in the accident statistics is due to a higher-than-average level of willingness to take risks. We discuss the major determinants of risk acceptance and present incentives for accident-free performance as the most effective method for bringing down the accepted level of risk while driving, and thus the frequency of accidents.

Nous savons que les conducteurs débutants sont surreprésentés dans les statistiques nationales d'accidents de la circulation. On recense le plus souvent deux fois plus d'accidents chez les conducteurs de moins de 25 ans proportionnellement à leur représentation dans la population générale. Ce taux d'accidents diminue à chaque nouvelle année de conduite. Nous savons également qu'environ la moitié de cette surreprésentation est due à l'inexpérience et que l'autre moitié est due à des caractéristiques propres au fait d'être jeune. Le manque d'expérience implique un niveau de compétences de conduite inférieur. Nous défendrons ici l'idée que cet état de fait est largement déterminé par deux caractéristiques. Premièrement, les conducteurs débutants présentent une déficience significative de l'aptitude à reconnaître les risques comme le font les conducteurs expérimentés. Deuxièmement, ils présentent une confiance trop importante dans leurs aptitudes à prendre en charge leur sécurité. Nous soutenons dans cet article que cette surreprésentation n'est pas due à leurs compétences limitées de manipulation du véhicule.

En conséquence, nous décrivons dans un premier temps une méthode d'enseignement qui irait dans le sens d'une accélération de l'acquisition de compétences de perception des risques. Dans un second temps, nous soutenons que la surreprésentation dans les accidents liée à l'âge des conducteurs est due à un niveau d'acceptation des risques supérieur à la moyenne. Nous discutons enfin des déterminants majeurs de l'acceptation des risques et nous présentons les incitations à des activités sans accidents en tant mesures les plus efficaces pour réduire le niveau de risque accepté, et donc la fréquence des accidents.

\section{INDEX}

Mots-clés: niveau de risque, risque cible, accident de la circulation, jeunes conducteurs, acceptation des risques, incitation à la sécurité

Keywords: level of risk, traffic accidents, novice drivers, risk acceptance, inexperience, target risk, incentives for safety 


\section{AUTHOR}

\section{GERALD J.S. WILDE}

Professor Emeritus, Department of Psychology, Queen's University, Kingston, Ontario, Canada K7L 3N6 